\title{
Absence of gemin5 from SMN complexes in nuclear Cajal bodies Le thi Hao ${ }^{1,3}$, Heidi R Fuller1, Le Thanh Lam¹, Thanh T Le ${ }^{2}$, Arthur HM Burghes ${ }^{2}$ and Glenn E Morris*1
}

\begin{abstract}
Address: ${ }^{1}$ Wolfson Centre for Inherited Neuromuscular Disease, LMARC Building, RJAH Orthopaedic Hospital, Oswestry, SY10 7AG, UK. and Institute of Science and Technology in Medicine, Keele University, ST4 7QB, UK, ${ }^{2}$ Dept. of Medical Biochemistry, Ohio State University, Columbus, OH 43210, USA and ${ }^{3}$ Center for Molecular Neurobiology, Ohio State University, Columbus, OH 43210, USA
\end{abstract}

Email: Le thi Hao - le.90@osu.edu; Heidi R Fuller - heidi.fuller@rjah.nhs.uk; Le Thanh Lam - lam.le@rjah.nhs.uk; Thanh T Le - le.44@osu.edu; Arthur HM Burghes - Burghes.1@osu.edu; Glenn E Morris* - glenn.morris@rjah.nhs.uk

* Corresponding author

Published: 18 July 2007

BMC Cell Biology 2007, 8:28 doi:10.1 |86/I47|-2I2I-8-28

This article is available from: http://www.biomedcentral.com/I47I-2I/2I/8/28

This is an Open Access article distributed under the terms of the Creative Commons Attribution License (http://creativecommons.org/licenses/by/2.0), which permits unrestricted use, distribution, and reproduction in any medium, provided the original work is properly cited.

\begin{abstract}
Background: Spinal muscular atrophy is caused by reduced levels of the survival of motor neurons (SMN) protein. SMN is found in large complexes with Sm proteins and at least eight other proteins, including seven "gemins". These complexes are involved in the assembly of snRNPs in the cytoplasm and their transport into the nucleus, but the precise roles of the individual protein components are largely unknown.
\end{abstract}

Results: We have investigated the subcellular distribution of gemins using novel antibodies against gemins 3-7, and existing mAbs against SMN, gemin2, unrip, fibrillarin and profilin II. Most gemins were equally distributed between nuclear and cytoplasmic fractions of HeLa cells, but gemin 5 and unrip were more abundant in the cytoplasm. In a cytoplasmic extract obtained by mild disruption of HeLa cells, nearly all the SMN and gemins 2-4 were in large complexes, but most of the gemin5 sedimented separately with a lower $S$ value. Most of the unrip sedimented with gemins 6 and 7 near the top of the sucrose density gradients, separate from both SMN and gemin5. Anti-SMN mAbs pulled down gemin 5 from cytoplasmic extracts, but not from nuclear extracts, and gemin 5 did not co-sediment with large SMN complexes in nuclear extracts. These data suggest that gemin 5 is easily detached from SMN-gemin complexes in the nucleus. By immuno-histochemistry, gemin 5 was rarely detectable in nuclear gems/Cajal bodies, although it was accessible to antibody and easily detectable when present. This suggests that gemin5 is normally absent from SMN complexes in these nuclear storage sites.

Conclusion: We conclude that SMN complexes usually exist without gemin5 in nuclear gems/ Cajal bodies. Gemin5 is believed to be involved in capturing snRNA into SMN complexes in the cytoplasm for transport into the nucleus. We hypothesize that gemin5, though present in the nucleus, is no longer needed for SMN complex function during the time these complexes are stored in gems/Cajal bodies.

\section{Background}

The SMN protein forms a stable complex with a group of proteins named gemins [reviewed in [1,2]]. The gemins colocalize with SMN in gems/Cajal bodies (CBs) and are 
also present throughout the cytoplasm and in the nucleoplasm [1], although gemin 4 has also been reported in the nucleolus [3]. An early view of the structure of the SMN complex was that gemins 2, 3, 5 and 7 bind directly to SMN, while gemins 4 and 6 associated by interaction with gemins 3 and 7, respectively [4]. It was later shown that a novel protein, gemin 8 , mediates the binding to SMN of the subcomplex of gemins 6 and 7 and a protein called unrip [5]. A recent study suggests that SMN interacts directly only with gemins 2,3 and 8 , while the subcomplex of gemin 7 with gemin 6 binds through gemin 8 , unrip binds through gemin7, gemin 5 binds through gemin2, and gemin 4 binds to both gemins 3 and 8 [2]. SMN complexes clearly have an important and well-documented role in both assembly of cytoplasmic snRNPs and their transport to the nucleus [5-8]. However, a significant amount of SMN is also found in the cytoplasm of motor neuron axons, suggesting that SMN may have motor neuron-specific functions independent of snRNP assembly [9-17].

Immunopurification of a 300-kDa SMN-gemin 2 complex showed that it also contained spliceosomal snRNP core proteins $\mathrm{B} / \mathrm{B}^{\prime}, \mathrm{D} 1, \mathrm{D} 2, \mathrm{D} 3, \mathrm{E}, \mathrm{F}$ and $\mathrm{G}[6]$. There is some controversy in the literature on whether there is an SMN interaction site for $\mathrm{Sm}$ core proteins near the C-terminus (residues $240-267$; [6]) or at residues $120-160$ in the exon3-encoded tudor domain [18]. Charroux et al [3] described an $800 \mathrm{kDa}$ complex that included SMN, gemin 2 and gemins 3 and 4 . Gemins 3 and 4 were also found without SMN in a separate $15 \mathrm{~S}$ complex that contains eukaryotic initiation factor $2 \mathrm{C}$ and numerous microRNAs [19]. Meister et al [20] isolated two distinct SMN complexes from HeLa nuclei, NSC1 and NSC2, that migrated in sucrose gradients at $20 \mathrm{~S}$ and $18 \mathrm{~S}$ respectively. NSC1 was U snRNA-free, but contained at least 10 proteins, including SMN, gemin2, gemins 3 and 4 and Sm proteins D1, D2 and F. They later described a complex in both nucleus and cytoplasm that contains all gemins and Sm core proteins, plus unrip and hsc70 [21]. Unrip is an interacting partner of unr, a cytoplasmic RNA binding protein involved in the translation of viral RNAs [22].

The functions of individual proteins in SMN complexes and how they contribute to the overall function of the complex remains unclear. A role for gemin2 in the oligomerization of the SMN complex was recently shown [24]. Gemin3 is a $103 \mathrm{kDa}$ RNA helicase that binds to Epstein-Barr virus-encoded nuclear antigens [25]. Its binding partner, gemin 4 , binds to protein phosphatase 4, overexpression of which can affect the localization of newly formed snRNPs in HeLa cells [26] and SMN phosphorylation is important for U snRNP assembly [27]. Gemin 4 was also found to interact with galectins 1 and 3, which are involved in mRNA splicing [28]. Gemin5 has thirteen WD domains which, in other proteins, form "propeller" structures involved in protein-protein interactions [29]. Gemins 6 and 7 fold together to form a structure that resembles Sm core protein dimers [30]. It has been suggested that gemin 6 and gemin 7 play a role in organizing Sm proteins for assembly onto snRNAs by serving as an Sm-like dimer surrogate around which individual Sm proteins are arranged for binding to the Sm site [30]. The gemin 6-7-8-unrip subcomplex is required for recruiting Sm core proteins to SMN complexes [5].

We have produced novel panels of antibodies against gemins and used them to investigate the subcellular and molecular distribution of gemins in the cell. The studies have revealed a striking deficiency of gemin 5 in nuclear gems/CBs and have shown that a large proportion of gemin 5 exists separately from SMN complexes.

\section{Results \\ Characterization of antibodies}

For this study, we produced new panels of monoclonal antibodies (mAbs) against gemins 4, 5, 6 and 7 (Table 1). We also produced a new polyclonal antibody against gemin3 to complement mAbs against SMN and gemin2 described previously [31]. Our first step was to demonstrate the specificity of the new antibodies by western blots of total HeLa cell proteins (Fig. 1). The anti-gemin3 serum gave a single band close to the expected size of 102 $\mathrm{kD}$; the GEM4D mAb against gemin4 $(97 \mathrm{kD})$ is shown alongside for comparison. Three gemin $4 \mathrm{mAbs}$ (GEM4B, $\mathrm{D}$ and $\mathrm{E}$ ) recognise a single band, apart from non-specific bands caused by the secondary antibodies, but the other three mAbs stain extra bands of higher Mr. The more specific mAbs were used in subsequent studies. All the gemin $5 \mathrm{mAbs}$ stained a band consistent with the predicted $\mathrm{Mr}$ of $167 \mathrm{kD}$. Only the C-terminal gemin $5 \mathrm{mAbs}$ (GEM5M-R) also stained a ladder of lower Mr bands down to about $60 \mathrm{kD}$; this may be due to partial degradation of gemin 5 in its N-terminal "WD-propeller" region. The N-terminal mAbs (GEM5A-L) were not useful for immunolocalization because they appear to recognize only denatured and unfolded protein on western blots (Table 1). In support of this, we were able to map the epitope for GEM5J to amino-acids 66-71 (RVSGFT) using phage-displayed peptide libraries as described previously [32] and this sequence is part of the highly-structured "WD-propeller" in the native state. Gemin6 mAbs stained a protein of $16 \mathrm{kD}$ and gemin $7 \mathrm{mAbs}$ a protein of $15 \mathrm{kD}$, both migrating slightly faster than predicted by their amino-acid sequence. Two of the gemin 6 mAbs crossreacted with higher Mr proteins, notably one of about 32 $\mathrm{kD}$. The more specific GEM6F was used in subsequent studies. We also used antibodies against other proteins known to interact with SMN including fibrillarin [33], unrip and profilin II [17]. 
Table I: Characterization of gemin monoclonal antibodies.

\begin{tabular}{|c|c|c|c|c|c|c|c|c|c|}
\hline \multirow[t]{2}{*}{ Clone } & \multirow{2}{*}{$\begin{array}{l}\text { Name } \\
\text { mAbs }\end{array}$} & \multirow[t]{2}{*}{ Sub class } & \multicolumn{5}{|c|}{ Western Blot } & \multicolumn{2}{|c|}{ IMF } \\
\hline & & & Recom & HeLa & cos7 & Pig & Fish & HeLa & cos7 \\
\hline IA8 & GEM4A & $\lg A$ & + & ++ & ++ & + & - & n.d. & n.d. \\
\hline IG4 & GEM4B & $\lg G \mid$ & + & ++ & ++ & + & - & + & + \\
\hline $9 \mathrm{E} 6$ & GEM4C & $\lg G 2 b$ & + & ++ & ++ & + & - & + & + \\
\hline $2 \mathrm{H} 8$ & GEM4D & $\lg G \mid$ & + & ++ & ++ & + & - & + & + \\
\hline $7 \mathrm{~B} 5$ & GEM4E & $\operatorname{lgG} 2 a$ & + & ++ & ++ & + & - & + & + \\
\hline $2 \mathrm{~A} 2$ & GEM4F & $\lg G 2 b$ & + & ++ & ++ & + & - & + & + \\
\hline IA5 & GEM5A & $\operatorname{lgGI}$ & + & ++ & + & - & - & - & - \\
\hline$|B|$ & GEM5B & $\lg G 2 a$ & + & ++++ & +++ & - & + & - & - \\
\hline $1 \mathrm{CIO}$ & GEM5C & $\lg G 2 b$ & + & + & + & + & - & - & - \\
\hline $2 \mathrm{~A} / 2$ & GEM5D & $\lg G 2 b$ & + & + & + & + & - & - & - \\
\hline $2 \mathrm{BII}$ & GEM5E & $\lg G 2 a$ & + & ++++ & ++ & - & + & - & - \\
\hline $5 C 3$ & GEM5F & $\lg G 2 a$ & + & ++ & ++ & - & - & - & - \\
\hline $6 C 4$ & GEM5G & $|g G|$ & + & ++ & ++ & - & + & - & - \\
\hline $6 \mathrm{E} 2$ & GEM5H & $\lg G 2 b$ & + & +++ & +++ & - & + & - & - \\
\hline $7 A I$ & GEM5I & $\operatorname{lgGI}$ & + & ++ & ++ & - & + & - & - \\
\hline $7 F I$ & GEM5J & $\lg G \mid$ & + & + & + & - & - & - & - \\
\hline $8 C 7$ & GEM5K & $\lg G 2 b$ & + & ++++ & +++ & - & + & - & - \\
\hline $8 \mathrm{E} 7$ & GEM5L & $\lg G 2 b$ & + & ++ & + & - & + & - & - \\
\hline$|E| 2$ & GEM5M & $\operatorname{lgG} \mid$ & + & +++ & ++ & ++ & - & + & + \\
\hline $2 \mathrm{E} 6$ & GEM5N & $\lg G \mid$ & + & ++++ & +++ & ++ & - & + & + \\
\hline $3 \mathrm{EII}$ & GEM5O & $\lg G \mid$ & + & +++ & ++ & ++ & - & + & + \\
\hline $3 G 2$ & GEM5P & $\lg G \mid$ & + & ++++ & +++ & ++ & - & + & + \\
\hline $4 \mathrm{G} 7$ & GEM5Q & $\lg G \mid$ & + & +++ & +++ & ++ & - & + & + \\
\hline $6 \mathrm{G} 5$ & GEM5R & $\operatorname{lgG} \mid$ & + & ++++ & +++ & ++ & - & - & - \\
\hline $2 \mathrm{CII}$ & GEM6A & $\lg G 2 a$ & + & + & + & - & - & + & + \\
\hline $4 \mathrm{H} 6$ & GEM6B & $\lg G 2 a$ & + & ++ & + & + & - & + & + \\
\hline $5 \mathrm{E} 9$ & GEM6C & $\lg G \mid$ & + & + & + & - & - & - & - \\
\hline $6 \mathrm{~F} 5$ & GEM6D & $\lg G 2 a$ & + & + & + & + & - & + & + \\
\hline $8 \mathrm{~A} 9$ & GEM6E & $\lg G 2 a$ & + & + & + & - & - & + & + \\
\hline 8D8 & GEM6F & $\lg G 2 a$ & + & ++ & + & + & - & + & - \\
\hline $3 \mathrm{FI} 2$ & GEM6G & $\lg G 2 b$ & + & + & + & - & - & + & - \\
\hline $2 \mathrm{AII}$ & GEM7A & $\operatorname{lgG} \mid$ & + & + & + & - & - & + & + \\
\hline $6 \mathrm{~A} 2$ & GEM7B & $\lg G \mid$ & + & +++ & ++ & - & - & + & + \\
\hline $6 \mathrm{~A} 9$ & GEM7C & $\lg G \mid$ & + & ++ & + & - & - & - & - \\
\hline $7 A 12$ & GEM7D & $\lg G \mid$ & + & ++ & + & - & - & + & + \\
\hline 8D8 & GEM7E & $\lg G \mid$ & + & + & + & - & - & + & + \\
\hline $8 \mathrm{HI}$ & GEM7F & $\lg G \mid$ & + & +++ & ++ & + & - & + & + \\
\hline $10 C 12$ & GEM7G & $\lg G \mid$ & + & + & + & - & - & + & + \\
\hline
\end{tabular}

\section{By immunolocalization, gemin5 is absent from nuclear gems/Cajal bodies in most cells}

We next needed to confirm that all the gemin antibodies stained gems or Cajal bodies (gems/CBs), as previously reported, and we found that most gemins colocalize with SMN in nuclear gems/CBs in HeLa cells, the exception being gemin5 (Fig. 2). Although colocalization of SMN and gemin 5 was observed in some cells (white arrows), gemin 5 was absent from gems/CBs in other cells in the same field of view (green arrows). Gems/CBs also lacked gemin5 in human Ntera-2 cells and skin fibroblasts. This was the first indication that gemin 5 may not always be associated with SMN. Although gemin $5 \mathrm{mAb}$ does not stain any SMN-positive gems/CBs in most nuclei, it stains the normal number of gems in the rare gemin5-positive nuclei. This "all or nothing" staining of gemin5 is illustrated in Table 2 where only positive nuclei were counted and the average gem count was 2.41 for gemin 5 compared with 2.5-2.6 for SMN and other gemins. To determine whether gemin 5 is associating with gems or CBs in the rare gemin5-positive nuclei, we used the HeLa PV cell line in which gems and CBs are separate (Fig. 3A) and found that gemin 5 colocalizes with SMN in gems (Fig. 3B \&3C), but not with coilin in CBs (Fig. 3D).

\section{Unlike other gemins, gemin5 is not co-regulated with SMN} SMN-containing gems/CBs are increased in number and brightness in a HeLa cell line overexpressing SMN protein, 

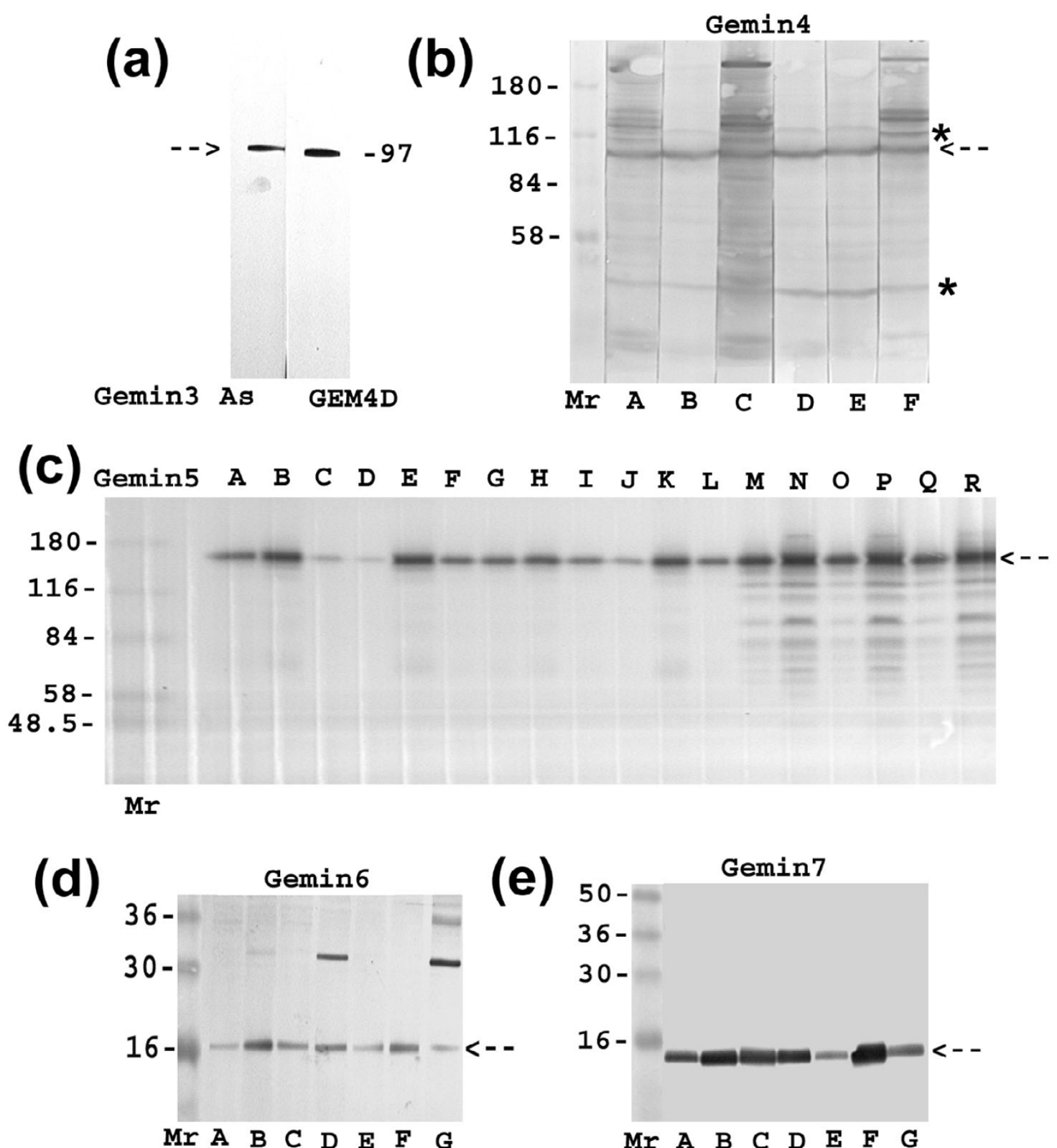

(e)

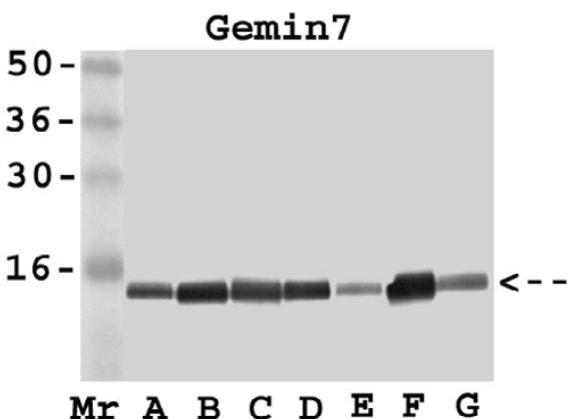

\section{Figure I}

Characterization of gemin antibodies by western blots of total HeLa cell proteins. An SDS extract of HeLa cells was run as a horizontal strip alongside Mr markers on SDS-PAGE and transferred to nitrocellulose membranes by electroblotting. 7\% acrylamide was used for (a)-(c) with prestained Sigma markers and I4\% for (d) and (e) with prestained SeeBlue markers. The blot was either cut into vertical lanes or, in (c) only, used directly on a 28-lane miniblotter apparatus. In each case, the main antigen band is shown as a broken arrow. (a) gemin3 antiserum stains a single protein of about $102 \mathrm{kD}$ (97 kD gemin4 is shown as a marker). (b) the panel of 6 gemin 4 mAbs all stain a band of $97 \mathrm{kD}$, but 3 of them (GEM4A, C and F) cross-react with several higher Mr proteins. Non-specific bands $\left(^{*}\right)$ are due to the secondary antibody system. (c) the $12 \mathrm{mAbs}$ against the gemin $5 \mathrm{~N}$-terminal region stain a single band consistent with the $167 \mathrm{kD}$ expected for gemin 5 and the $6 \mathrm{mAbs}$ against the $\mathrm{C}$ terminal region stain the same band, together with a ladder of smaller bands that may be degradation products. (d) The 7 gemin $6 \mathrm{mAbs}$ all stain a band of $16 \mathrm{kD}$, but 2 of them cross-react with a $32 \mathrm{kD}$ band. (e) All 7 gemin7 mAbs stain a single band of $15 \mathrm{kD}$. 

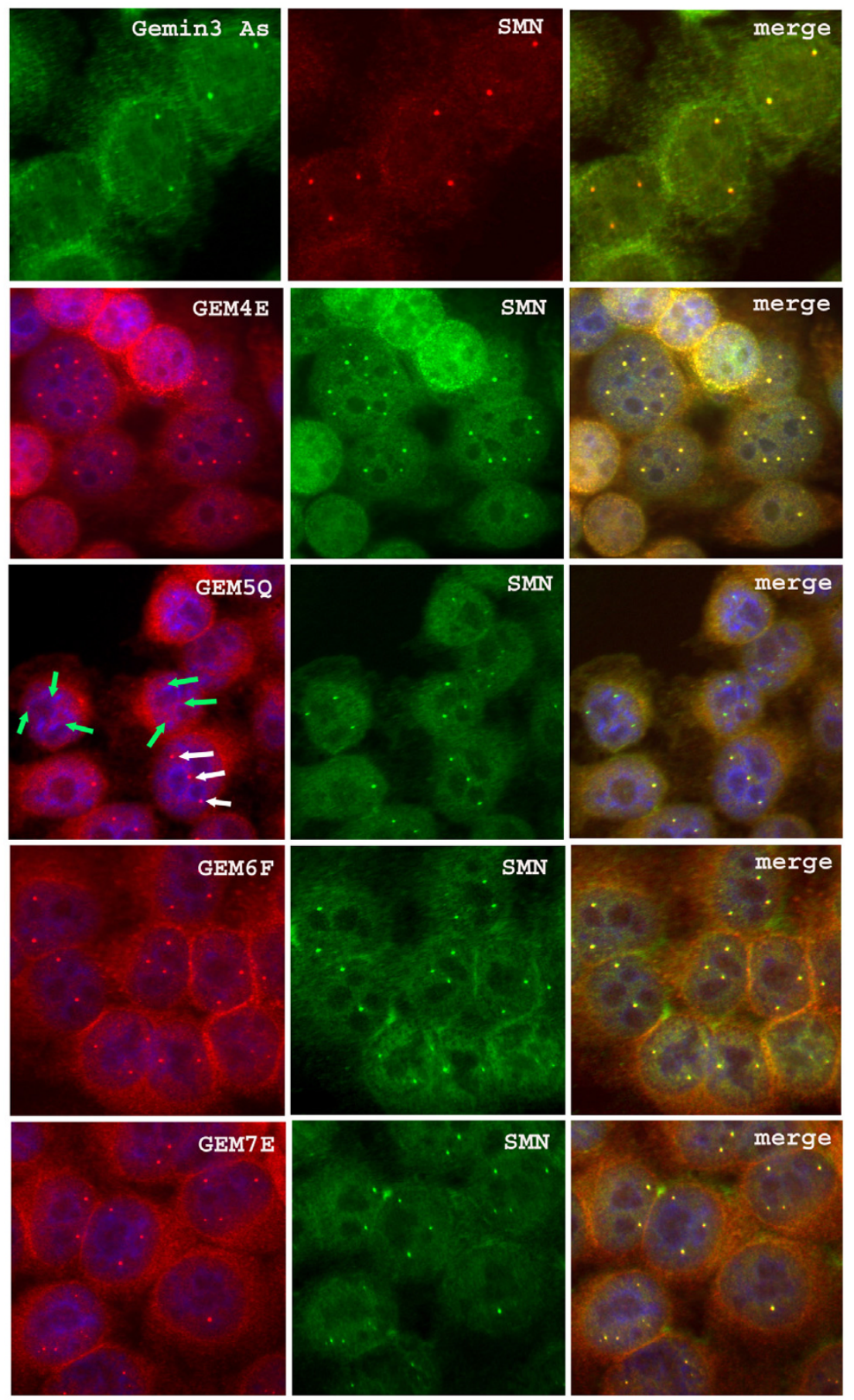

\section{Figure 2}

Gemins 3, 4, 6 and 7 colocalise with SMN in nuclear gems/CBs, but gems/CBs in most cells lack gemin5. HeLa cells grown on coverslips were fixed with I\% formalin in PBS and permeabilized with I\% Triton X-100. Gemins 4, 5, 6 and 7 were identified using GEM4E, GEM5Q, GEM6F and GEM7E, respectively in a double label with SMN rabbit antiserum. Typical fields are shown, except that an unusual field containing several cells with gemin5-positive gems/CBs was chosen for GEM5Q. The anti-gemin3 rabbit antiserum was double-labelled with MANSMAI mAb against SMN. Alexa fluor 546 goat anti-mouse lgG (red) and Alexa fluor 488 goat anti-rabbit lgG (green) were used as second antibodies. DAPI (blue) was used to counterstain the nuclei. (See text for white and green arrows). 
Table 2: Gemin5 staining is "all or nothing".

\begin{tabular}{cccc}
\hline mAb & Number of nuclei with gems/CBs & Total number of gems/CBs & $\begin{array}{c}\text { Average number of gems/CBs per } \\
\text { positive nucleus }\end{array}$ \\
\hline MANSMAI & 113 & 290 & 2.57 \\
MANSIPIA & 93 & 242 & 2.60 \\
GEM4E & 103 & 257 & 2.50 \\
GEM5Q & 27 & 65 & 2.41 \\
GEM6F & 114 & 286 & 2.51 \\
GEM7E & 111 & 280 & 2.52 \\
\hline
\end{tabular}

In those rare HeLa cell nuclei that have gemin5-positive gems/CBs, nearly all gems/CBs were positive for gemin5. HeLa cell cultures on glass coverslips were fixed with 50:50 acetone: methanol, dried and labelled individually with gemin mAbs. Only nuclei with positive gem/CB staining were counted.

so we set out to determine whether antibody staining of these structures for gemins was also increased. Gemins 2, 3, 4, 6 and 7 did colocalize with SMN in these up-regulated gems/CBs, but gemin 5 was still not detected in these structures (Fig. 4ab). Fig. 4b shows that unrip also colocalises with the up-regulated gems/CBs and that traces of fibrillarin, a predominantly nucleolar protein, can also be detected in the up-regulated gems/CBs (at such low levels, however, the possibility of a slight cross-reaction of this auto-antiserum cannot be entirely ruled out). Fig. 4b also confirms earlier evidence [31] that coilin, the marker for Cajal bodies, is up-regulated in gems/CBs when SMN levels are increased by transfection.

SMN on western blots was decreased to $30-40 \%$ of control levels in cultured skin fibroblasts derived from an SMA type I patient (Fig. 5). Most gemins were also decreased by a similar proportion, but gemin 5 showed a
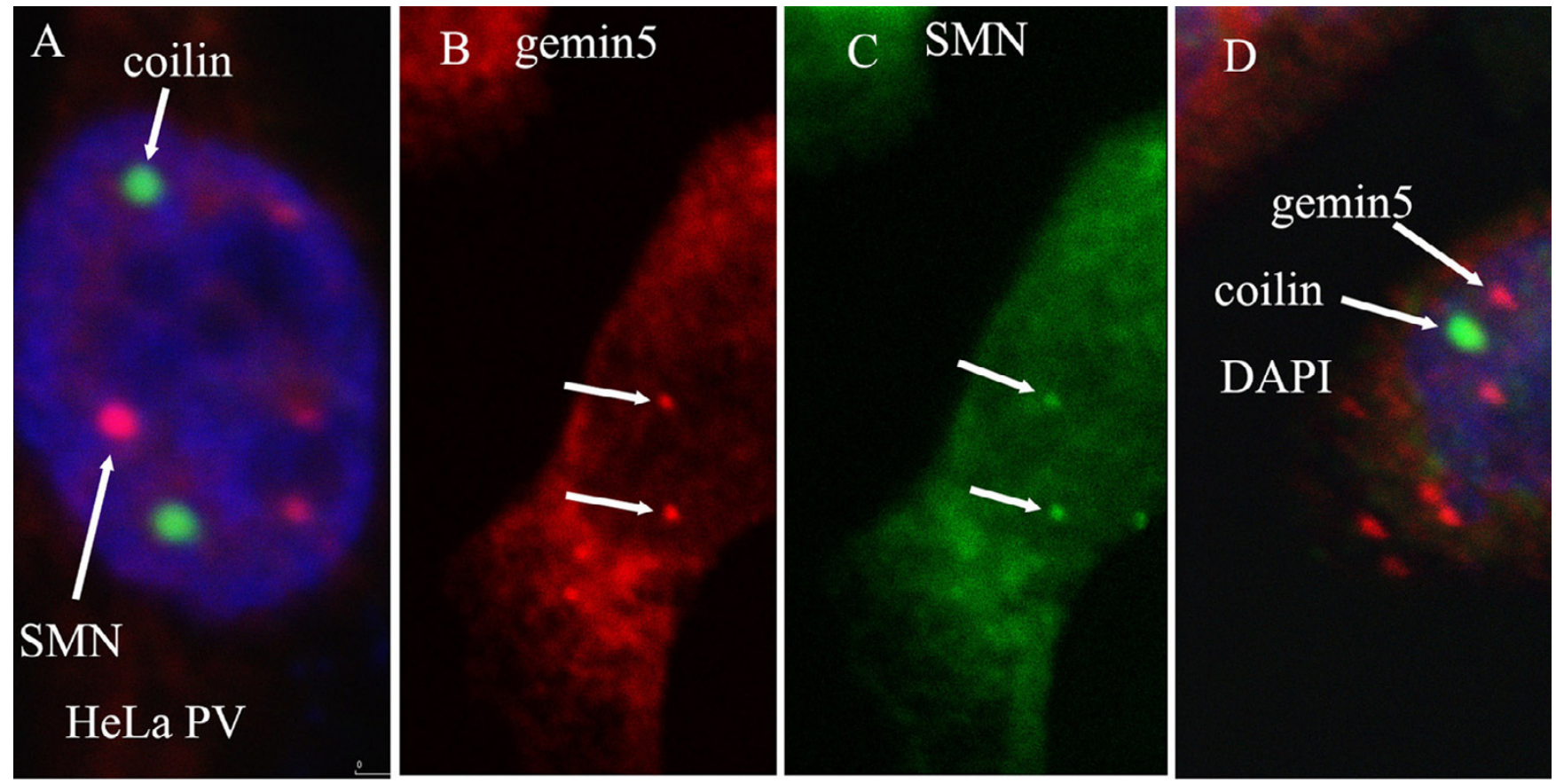

\section{Figure 3}

In Hela PV cells, which have separate gems and CBs, gemin5 colocalizes with gems, not CBs, in those rare cells that do have gemin5-positive nuclear bodies. HeLa strain PV cells grown on coverslips were fixed with $1 \%$ formalin in PBS and permeabilized with I\% Triton X-I00. (A) Separation of gems (red: MANSMAI mAb and Alexa-546 anti-mouse Ig) and CBs (green: rabbit anti-coilin and FITC anti-rabbit Ig) in HeLa PV, counterstained with DAPI (blue). Rare gemin5-positive nuclear bodies were double-labelled with (B) mAb GEM5P and Alexa-546 anti-mouse Ig and (C) rabbit anti-SMN and FITC antirabbit Ig to show colocalization of SMN and gemin5 (white arrows). (D) is an overlay from a double label with GEM5P (red) and rabbit anti-coilin (green) with a DAPI counterstain (blue), showing no colocalization. 


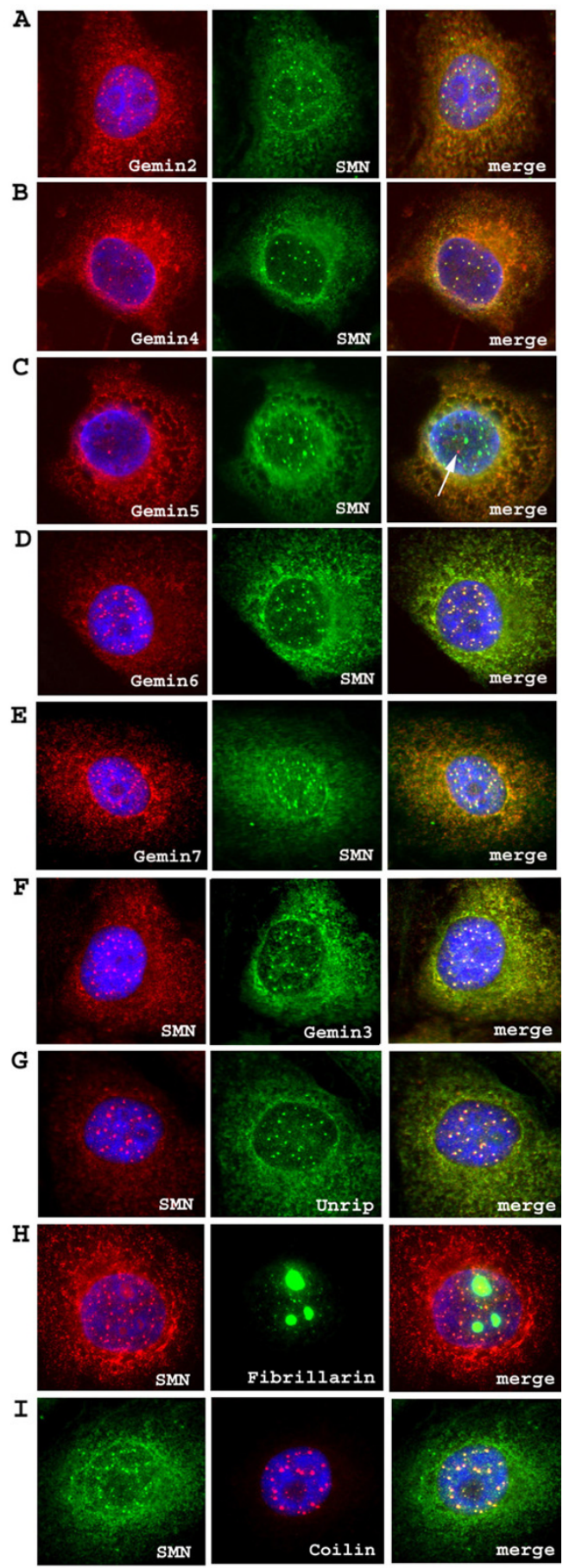

\section{Figure 4}

Overexpression of SMN in HeLa cells stimulates formation of gems/CBs containing other gemins, except gemin 5. Gemin2 (A), gemin $4(B)$, gemin6 (D) and $7(E)$ co-localise with SMN in HeLa cells stably transfected with human SMNI in pcDNA3 [49]. Gemin5 (C) does not co-localise with SMN. The same mAbs as in Fig. 2 were used, plus MANSIPIA for gemin2. Double label of SMN mAb MANSMAI with gemin3 rabbit antiserum (F), unrip rabbit antiserum (G) and fibrillarin human auto-antiserum $(\mathrm{H})$, or SMN antiserum with $\mathrm{p} 80 \mathrm{mAb}(\mathrm{I})$ were performed on the HeLa cell line stably transfected with SMNI. Alexa fluor 546 goat anti-mouse IgG (red) was used to detect mouse mAbs and Alexa fluor 488 goat anti-rabbit lgG (green) was used to detect rabbit antibodies. FITC-conjugated goat anti-human IgG (Chemicon) was used to detect fibrillarin. DAPI (blue) was used to counterstain the nuclei. 
smaller reduction (Fig. 5). These reductions in SMA fibroblasts were also evident by immunofluorescence microscopy (Fig. 6). SMN and most gemins showed drastically decreased levels in both nuclear gems and cytoplasm in SMA fibroblasts. Gemin5, however, remained stable in the cytoplasm, consistent with the western blot data in Fig. 5 and with the existence of a separate pool of gemin5, independent of SMN.

\section{Unlike other gemins, gemin5 is present mainly in the cytoplasm}

We next examined the distribution of SMN and gemins between nucleus and cytoplasm using a simple cell fractionation followed by western blotting (Fig. 7). To minimise quantitation problems with X-ray film exposure, we used $100 \%, 50 \%$ and $25 \%$ dilutions of each extract and compared the closest match by microdensitometry. Comparisons can only be reliably made between fractions of the same protein, and not between different proteins, because of possible differences in antibody avidity. In HeLa cells, SMN and most gemins were equally distributed between nucleus and cytoplasm, but gemin 5 was predominantly cytoplasmic. This could mean that gemin 5 has additional SMN-independent functions in the cytoplasm, but it is also possible that gemin 5 is turned over in, or exported from, the nucleus more quickly than other gemins. HeLa cells are widely used for SMN studies but it would be unwise to assume that they are representative of human cells in general. In the neurogenic cell line, Ntera2, we found that SMN and gemins were much more cytoplasmic than in HeLa cells. In both skin fibroblasts and Ntera-2 cells, gems/CBs were rarely, if ever, stained by anti-gemin 5 mAbs (data not shown).

\section{On sucrose density gradient analysis, gemin5 is absent from SMN complexes in nuclear extracts, but not in cytoplasmic extracts}

The extent to which gemin 5 and other gemins are present in complexes with SMN was studied by sucrose density gradient centrifugation. We analysed a total extract of HeLa cells prepared using a RIPA buffer and an extract separated into nuclear and cytoplasmic fractions using the established method of Meister et al [20]. These experiments were repeated three times starting with fresh HeLa cells and a representative result is shown in Fig. 8. It seems likely that some detachment of proteins from the SMN complexes occurs during cell lysis or fractionation with the harsher RIPA or high-salt nuclear buffers. Thus, no $\mathrm{SMN}$ or gemin2 is seen at the top of the gradient in lowsalt cytoplasmic extracts (Fig. 8b) but they are present when RIPA buffer (Fig. 8a) or higher salt (Fig. 8c) are used. The mild extraction used for the cytoplasmic fraction is more likely to yield intact SMN complexes (Fig. 8b) but, although most of the SMN and gemins 2, 3 and 4 sedimented in large complexes, the majority of both gemin 5 and unrip remained in the upper part of the gradient $(<19 S)$, together with a significant proportion of gemins $6 / 7$. This would be consistent with these latter proteins having some additional functions outside SMN complexes.

Successful subcellular fractionation is shown by the presence of nuclear markers, such as lamin A/C, emerin, coilin p80 and fibrillarin, only in the nuclear fraction while profilin II was present only in the cytoplasmic fraction. As expected, all gemins and unrip are partly present in large complexes migrating near the bottom of the sucrose gradient, whereas other nuclear protein markers, emerin and lamin $\mathrm{A} / \mathrm{C}$, remained in the upper half of the gradient. Fibrillarin is clearly sedimenting in high molecular weight complexes but since most fibrillarin is in the nucleolus and very little colocalizes with $\mathrm{SMN}$, this material seems unlikely to represent complexes with SMN. SMN, however, does colocalize with fibrillarin in the nucleolus in fetal tissues [34] and the possibility that SMN is complexed with fibrillarin in a "masked" form [35] in HeLa nuclei has never been ruled out. The proteins in the upper half of the gradients would be consistent in size with monomers or small homo- or hetero-oligomers. Thus, gemins 6 and $7(15-19 \mathrm{kD})$ are in the first two fractions, while SMN and gemin2 (32-38 kD) co-sediment close to the $7 \mathrm{~S}$ marker. Gemin5 (167 kD) monomers would be expected around $7 \mathrm{~S}$ and its faster sedimentation at around $11 \mathrm{~S}$ might be consistent with a proposed trimeric structure [29].

Gemin5 did not co-sediment at all with the large SMN complexes in the nuclear extract (Fig. 8c), consistent with its absence from gems/CBs (Fig. 2). However, the possibility that gemin 5 detached from the complexes during fractionation cannot be ruled out. In a recent study, gemin 5 was more easily detached by high salt than other gemins [2], though this occurred at higher salt concentrations (>500 $\mathrm{mM}$ ) than those used for nuclear extraction (440 $\mathrm{mM}$ total). Adding extra $\mathrm{KCl}$ to cytoplasmic extracts to $440 \mathrm{mM}$ did not dissociate gemin 5 from SMN (see Fig. 9b below), but the possibility that nuclear complexes are less stable cannot be ruled out. Therefore, we have restricted our major conclusions to the clear invivo reduction of gemin5 in nuclear gems/CBs by immunolocalization studies (Fig. 2), which cannot be explained by fractionation artefacts, and to the complexes present under mild extraction conditions (Fig. 8b).

\section{Gemins co-sedimenting on sucrose gradients form true complexes in which all gemins are accessible to antibody} Immunoprecipitation experiments were performed to demonstrate true complex formation, as opposed to Cosedimentation on the sucrose gradients. MANSMA1 antiSMN mAb pulled down gemin5 from cytoplasmic com- 


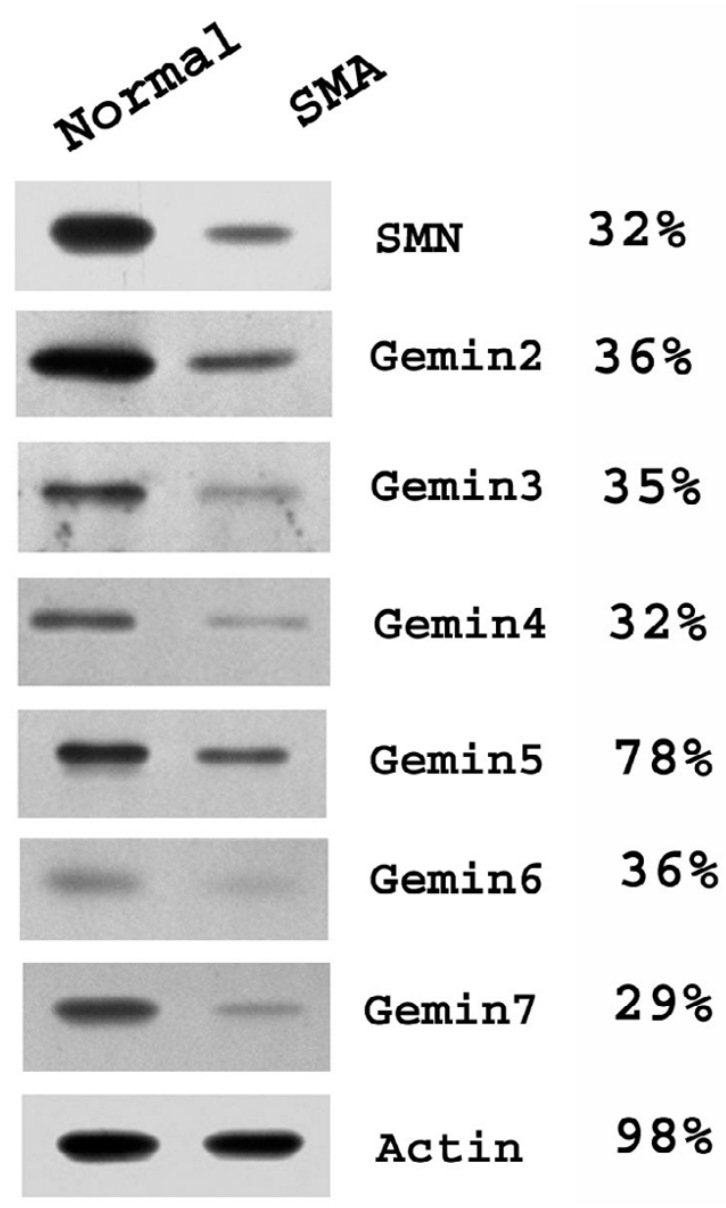

Figure 5

All gemins, except gemin5, are proportionately reduced in SMN-deficient human skin fibroblasts. Total SDS extracts of the two skin fibroblast cell lines (Coriell cell lines, GM08333, control and GM038I3, SMA) were subjected to SDS-PAGE on adjacent lanes of a $7 \%$ or $14 \%$ acrylamide gel (cf. Fig. I), followed by western blotting with the same antibodies used in Fig. 2 plus MANSIPIA for gemin2. $\beta$-actin was used as a control for equal loading of the gel lanes. Microdensitometry was used to express protein levels in SMA fibroblasts as a percentage of those in control fibroblasts.

plexes only, in agreement with sucrose gradient data (Fig. 8), whereas it pulled down SMN itself and the gemin4 control from both nuclear and cytoplasmic complexes (Fig. 9a). To determine whether the absence of gemin5 from SMN complexes in nuclear extracts was due to disruption by high salt, cytoplasmic extracts were studied after adding $\mathrm{KCl}$ to the same concn as the nuclear extracts and gemin 5 was still pulled down by the anti-SMN mAb (Fig. 9b). To show that all gemins are accessible to antibody in SMN complexes, the immunoprecipitation experiment was reversed and various anti-gemin mAbs were used to pull-down endogenous SMN protein from a total
HeLa extract in RIPA buffer. This extract contains both nuclear and cytoplasmic complexes, and all gemin mAbs, including gemin5, pulled down SMN (Fig. 9c). The predictable exception was a mAb that only recognizes denatured gemin 5 on blots and would not be expected to bind native complexes. This experiment confirms that gemin5 in SMN complexes is as accessible to antibody as the other gemins and shows that masking of gemin 5 epitopes cannot explain the absence of gem/CB staining by gemin 5 mAbs in immunofluorescence microscopy (Fig. 2).

\section{Discussion and conclusion}

The idea that SMN complexes may vary in composition is not a novel one. Dreyfuss and co-workers have explained their own data in terms of a range of structures from SMNgemin2 heterodimers upwards [36]. It is also implicit in the studies of Meister et al $[20,21]$. The possibility that compositional changes may be relevant to understanding the function of SMN complexes has not, however, been fully explored, partly because the roles of the SMN complex and its individual protein components are still not fully understood and partly because of the uncertainty about the stability of complexes after cell disruption for biochemical studies.

In the present study, sucrose gradient analysis has shown that SMN complexes in nuclear extracts have little or no gemin5. This was also noted in an earlier study [27]. Pulldown experiments with anti-SMN mAb confirmed that SMN is associated with gemin 5 in cytoplasmic extracts but not in nuclear extracts. A major problem with subcellular fractionation, however, is the difficulty in ruling out possible dissociation during biochemical fractionation, with some components of SMN complexes being more easily dissociated than others. In our hands, raising the salt concn in cytoplasmic extracts to $440 \mathrm{mM}$ (same as nuclear extracts) did not noticeably dissociate gemin 5 from SMN and this agrees with a recent study showing that a higher concentration ( $>500 \mathrm{mM}$ ) is required to do this [2]. Even so, we cannot rule out the possibility that some dissociation of SMN complexes has occurred in nuclear extracts.

Therefore, the observation in intact cells that gemin 5 does not colocalize with SMN and all other gemins in nuclear gems/CBs is important to show that its absence from complexes is not just an artefact of biochemical fractionation. It is significant that gemin 5 was found in gems/CBs in a very small proportion of HeLa cells $(<1 \%)$ and that, when present, it was present in all gems/CBs of that nucleus. This is a key observation since it shows that gemin 5 is easily detected by immunofluorescence microscopy, when it is present. It also suggests that these minority cells may differ metabolically or phenotypically from the majority. The possibility that binding of mAbs to gemin5 was masked by other components of the SMN complex is 
Normal
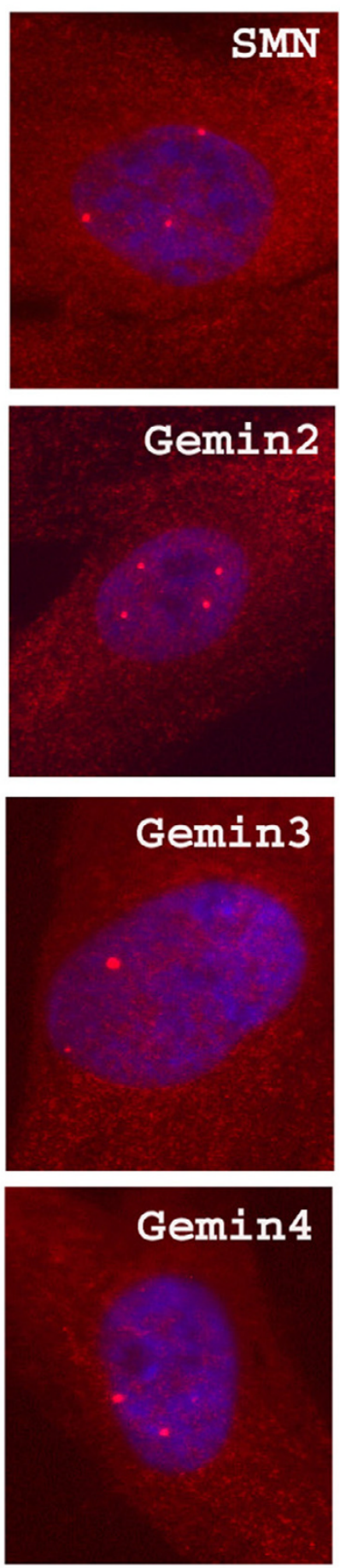

SMA
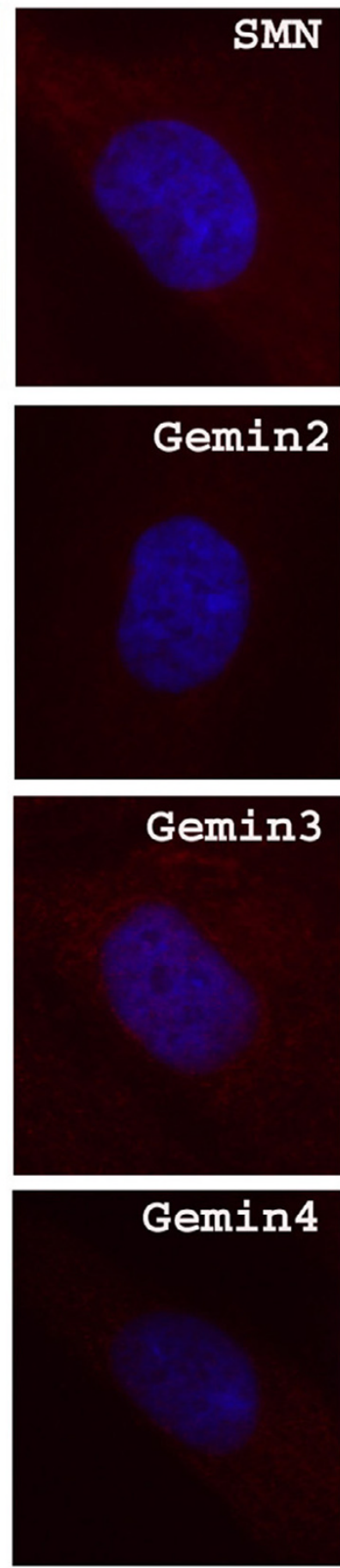

Normal
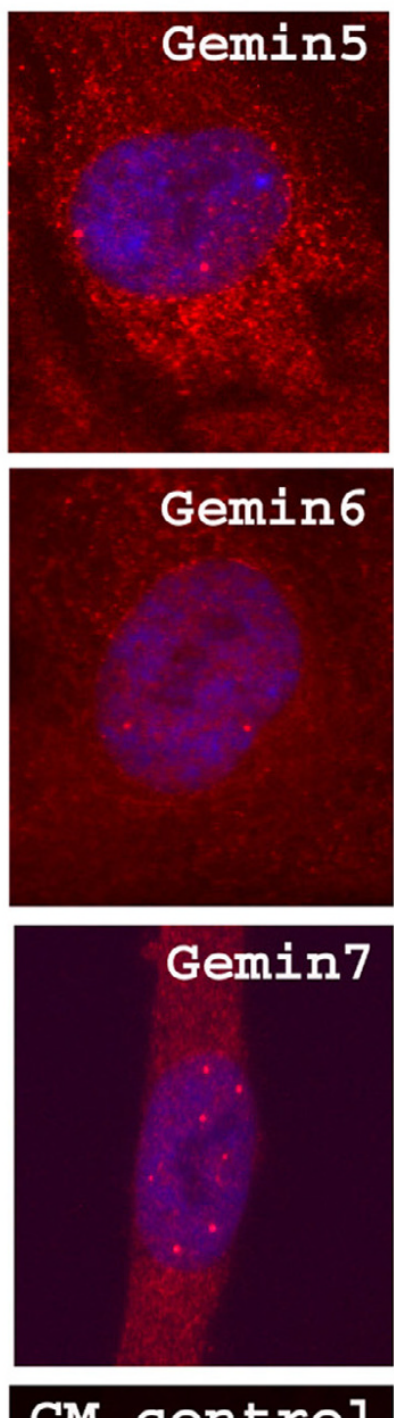
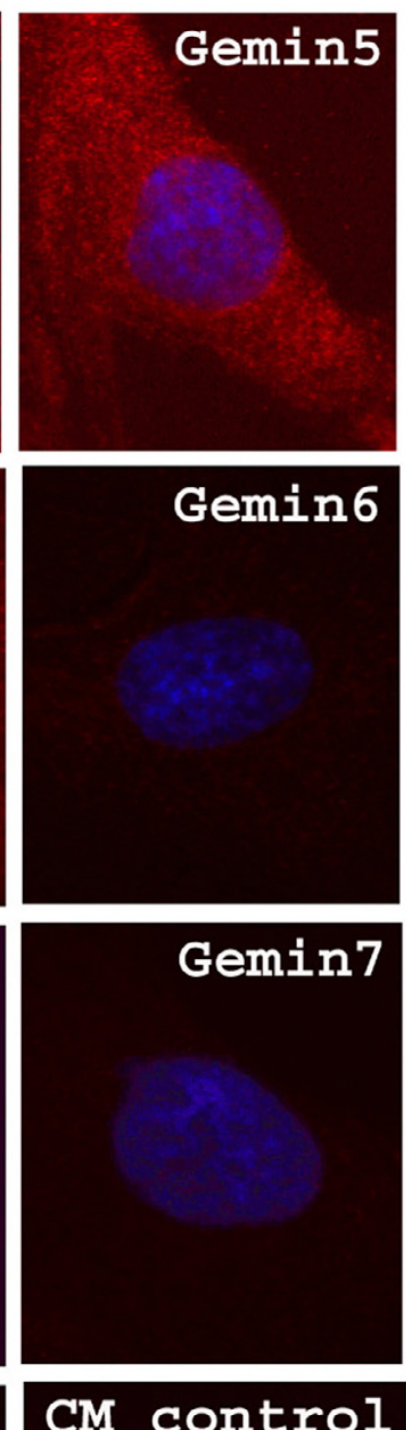

Figure 6

Nuclear gems/CBs and cytoplasmic levels of most gemins are greatly reduced in SMN-deficient human skin fibroblasts, but cytoplasmic gemin 5 levels remain high. Alexa fluor 546 goat anti-(mouse $\lg G$ ) (red) was used to detect SMN and gemin 2, 4, 5, 6 and 7 primary mAbs (the same mAbs as in Fig. 2). TRITC donkey anti-(rabbit Ig) was used to detect anti-gemin 3 rabbit antibodies. DAPI (blue) was used to counterstain the nuclei. 


\section{HeLa C HeLa N}
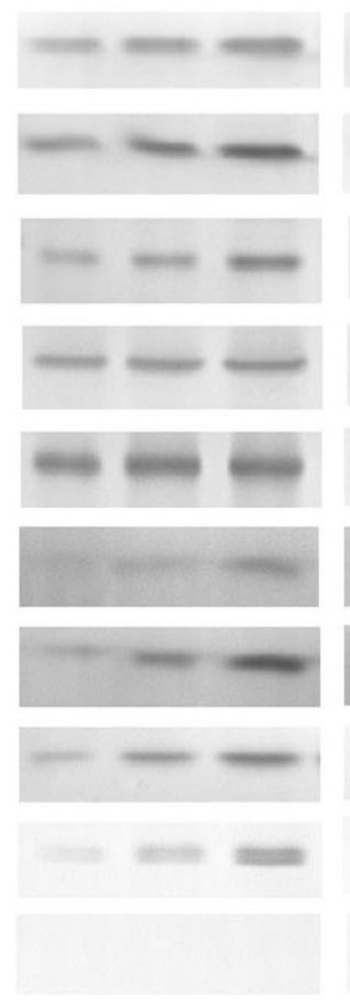
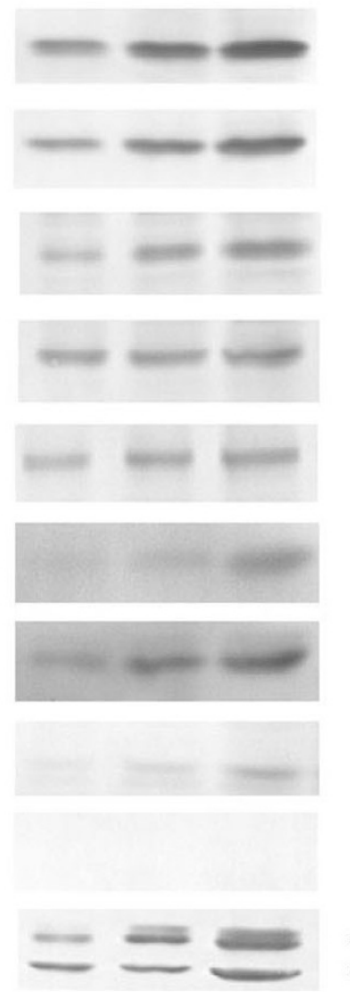

\section{SMN}

Gemin2

\section{Gemin3}

Gemin4

\section{Gemin5}

Gemin6

Gemin 7

Unrip

$\gamma$ tubulin

Lamin A/C

\section{Ntera C Ntera $\mathbf{N}$}
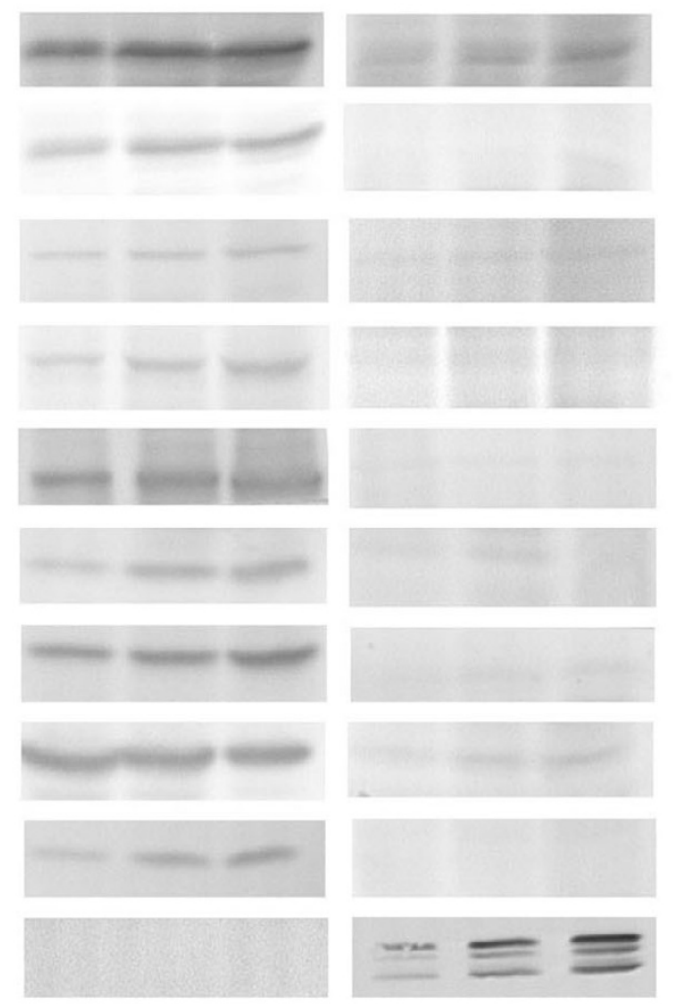

\begin{abstract}
Figure 7
Distribution of gemins and other proteins between cytoplasmic and nuclear fractions of HeLa and $\mathrm{Ntera2}$ cells. HeLa $C$ and Ntera $C$ are cytoplasmic fractions, HeLa $N$ and Ntera $N$ are nuclear fractions. After extraction with cytoplasmic buffer (see Methods), the whole pellet was boiled in SDS sample buffer to obtain the "nuclear" extract. Samples were loaded as serial dilutions (from left to right, I/4, I/2 and I) for more accurate microdensitometry quantitation. $\gamma$ tubulin and lamin $\mathrm{A} / \mathrm{C}$ were used as controls for cross-contamination between nuclear and cytoplasmic fractions.
\end{abstract}

ruled out by the fact that the same gemin $5 \mathrm{mAbs}$ are as capable of immunoprecipitating SMN as mAbs against other gemins (Fig. 9c). Overexpression of SMN in a stablytransfected HeLa cell line increases the number and brightness of nuclear gems/CBs when stained with SMN antibodies or with most other gemin antibodies, but it did not bring about increased immunostaining of gemin 5 in gems/CBs, which we might expect if the gemin 5 mAbs were simply rather weak in immunostaining. We hypothesize that the most important role of gemin 5 is in the cytoplasmic part of the SMN cycle and that its role becomes less important once the assembled snRNPs have been transported to the nucleus by the SMN complex. Gubitz et al [29] have suggested that the WD propeller structure of the gemin $5 \mathrm{~N}$-terminal domain may act as an assembly platform for other proteins and recent reports suggest that gemin5 is involved in binding the snRNA component for snRNP assembly [37].
It is also of interest that, even in the cytoplasm, a significant proportion of the gemin 5 is unassociated with SMN complexes. This is evident both from the sucrose gradients in Fig. 8b and from the fact that both cytoplasmic gemin 5 staining and gemin 5 levels on western blots remain strong in type I SMA fibroblasts, when SMN and other gemins are clearly reduced by $60-70 \%$ relative to control fibroblasts. Similarly, RNAi knockdown of SMN had comparatively little effect on gemin5 levels (cf. Fig. 2A of Feng et al, [38]). Feng et al [38] also showed that RNAi knockdown of gemin 5 did not affect gems/CBs or the levels of other SMN complex components on western blots. Similarly, Shpargel and Matera [39] found that RNAi knockdowns of SMN or gemins 2, 3 or 4 all disrupted Sm core protein assembly, whereas knockdown of gemin 5 had no effect. These observations are consistent with our data, though the presence of a larger cytoplasmic pool of "free" gemin5 could mean that a much more efficient knockdown of 

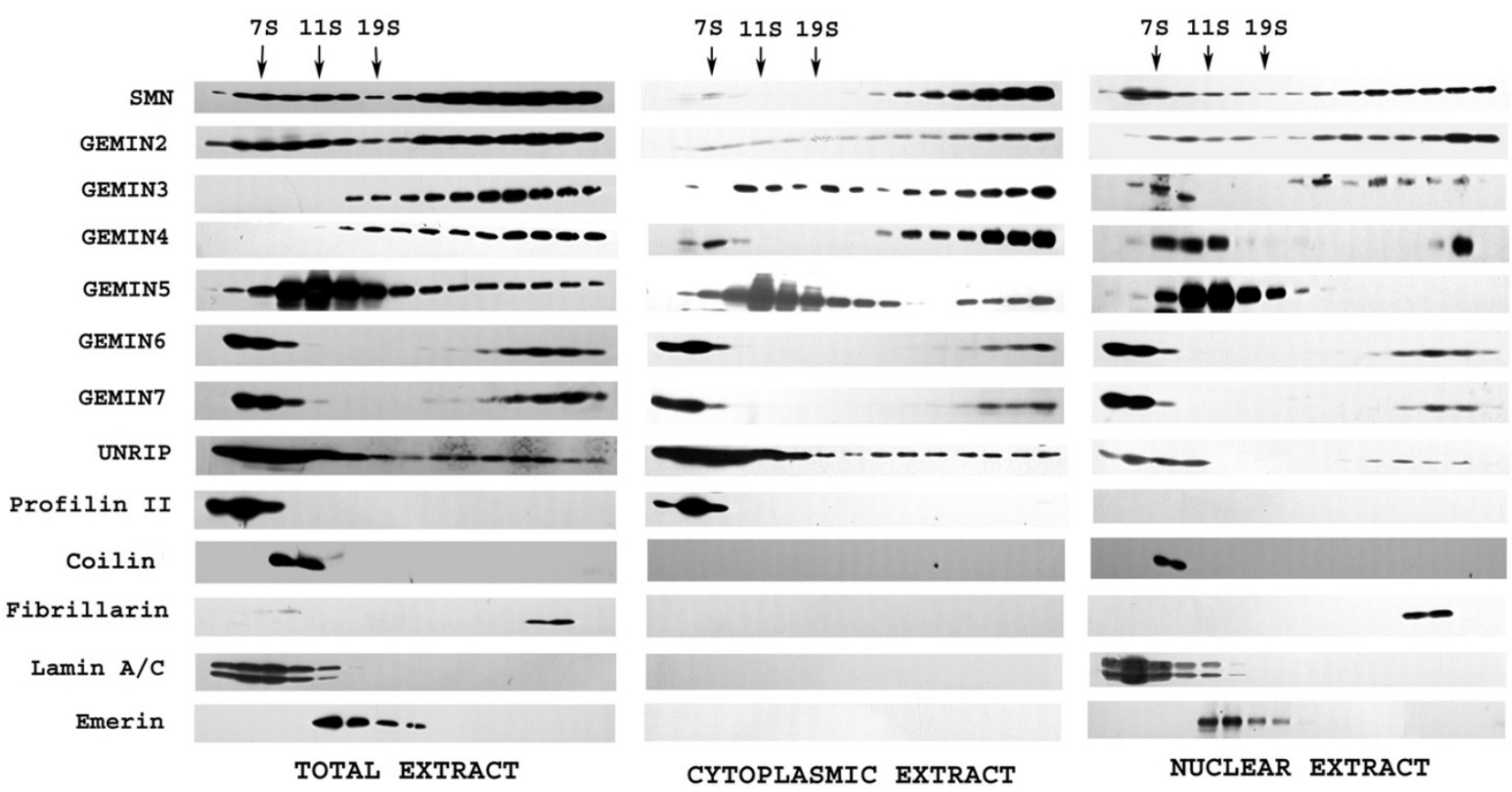

Figure 8

Distribution of SMN and gemins between large, fast-sedimenting SMN complexes and slower sedimenting fractions. HeLa total, cytoplasmic and nuclear extracts were prepared and analyzed by centrifugation on $15-30 \%$ sucrose density gradients. Thirty I ml fractions were collected from each gradient and the protein contents were concentrated into $0.1 \mathrm{ml}$ using Strataclean resin. Every other fraction (I, 3, 5, etc) was subjected to SDS-PAGE for western blotting using appropriate antibodies. The size markers were immunoglobulin (7S), catalase (IIS) and thyroglobulin (I9S).

gemin 5 would be required to obtain the same result as other gemin knockdowns.

An excess of "free" gemin 5 over that required for SMN complexes might imply a more general role for gemin5. An interaction with eukaryotic initiation factor $4 \mathrm{E}$ has recently been described and a role for gemin 5 in assembly or processing of messenger RNP complexes was suggested [40]. In their study, mass spectrometry did not reveal SMN or any other gemins in these gemin 5 complexes. The possibility that gemin 5 may have a more general role in RNP assembly was raised by Gubitz et al [29]. Unrip is another WD-repeat protein, like gemin5, and it also has a clearlydemonstrated role in mRNA translation initiation [22]. A further role for unrip in assembling mRNA export and transport intermediates has recently been proposed [41]. Carissimi et al [23] and Grimmler et al [42] also found that unrip, like gemin5 in the present study, was predominantly cytoplasmic and not localized in nuclear gems/ CBs. Our results confirm the mainly cytoplasmic distribution of unrip (Fig. 8), but a small amount of unrip in the nuclear fraction was present in large complexes (Fig. 8) and was detectable in nuclear gems/CBs of HeLa cells overexpressing SMN (Fig. 4G). These differences between laboratories could be due to antibody avidity or SMN expression levels and a consensus may be that both of these two WD-repeat proteins, gemin5 and unrip, are present at relatively low, often undetectable, levels in gems/CBs. It may be that both proteins are involved in assembling complexes of SMN with RNA and other proteins but are no longer essential when the complexes arrive in nuclear gems/CBs.

Although SMN and profilin II interact in vitro and are both detectable in nuclear gems/CBs in neuronal cells [17], we found no evidence for the presence of profilin II in the SMN-containing complexes (Fig. 8), possibly because the interaction is weaker and profilin I may be the dominant isoform in HeLa cells. Coilin was not found in the large SMN complexes, although a methylated form can interact with SMN [43] and it does colocalize with nuclear SMN in gems/Cajal bodies in most HeLa cell lines. However, SMN and coilin p80 can also form quite separate gems and Cajal bodies in fetal tissues [34] and coilin p80 is exclusively nuclear, so the result is not altogether surprising. SMN complexes involve so many proteins, even the "core" complex let alone ancillary interactors, that much work remains to be done in elucidating what exactly is binding to what under different cellular conditions $[1,2]$. There is evidence, for example, that 


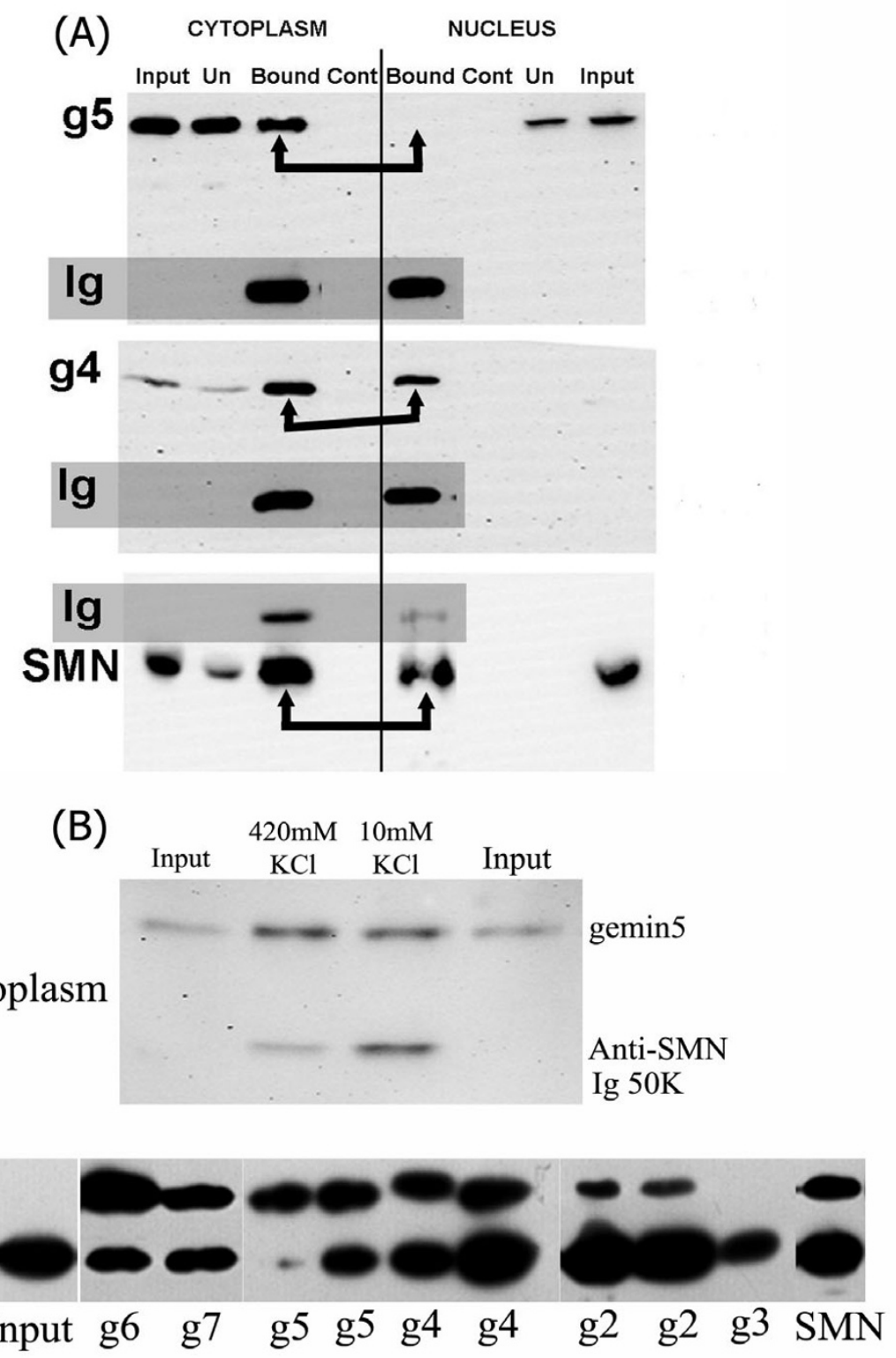

Figure 9

(A) Co-immunoprecipitation with MANSMAI anti-SMN mAb shows that SMN and gemin5 exist as complexes in cytoplasmic extracts, but not in nuclear extracts (arrows show lanes to be compared). SMN and gemin4 controls are pulled down from both extracts equally. (B) Addition of $\mathrm{KCl}$ to the cytoplasmic extract to the same concentration as nuclear extraction buffer did not disrupt the SMN-gemin5 interaction. (C) All gemins in SMN complexes were accessible to appropriate antibodies. All anti-gemin antibodies pulled down SMN from total RIPA extracts of HeLa cells, except GEM5G which only recognizes denatured gemin 5 on western blots (this also acts as a negative control). Antibodies were (left to right; see Table I): No mAb (input control), GEM6B, GEM7B, GEM5G, GEM5P, GEM4C, GEM4D, MANSIPIB, MANSIPIA, rabbit anti-gemin3 and MANSMAI. In each case, $0.05 \mathrm{ml}$ of Dynabead magnetic beads (Dynal, Oslo, Cat. No. 100.4I), with anti-mouse Ig (or anti-rabbit Ig) attached covalently, were incubated with $0.1 \mathrm{ml}$ of undiluted $\mathrm{mAb}$ culture supernatant (or $1 / 100$ dilution antiserum) for I h at $4^{\circ} \mathrm{C}$, washed $3 \times$ with PBS containing $0.1 \% \mathrm{BSA}$, and then incubated for $16 \mathrm{~h}$ at $4^{\circ} \mathrm{C}$ with $0.08 \mathrm{ml}$ of HeLa extract (also sampled as "input"). After removing the "unbound" extract, the beads were washed $5 \times$ with PBS and boiled in $0.02 \mathrm{ml}$ of SDS sample buffer. Gels ( $10 \%$ or $12.5 \%$ polyacrylamide) were loaded with $0.01 \mathrm{ml}$ of SDS extract for SDS-PAGE and western blotting with anti-SMN mAb MANSMAI2, as described in Methods. All lanes loaded with SDS extracts of beads contain a 50 KDa band of mouse Ig heavy chain which reacts with the HRP anti-mouse Ig used to develop the blot (band is absent from input and when rabbit antisera are used on beads). 
Table 3: Oligonucleotide primers for PCR

\begin{tabular}{cc}
\hline Primer & Primer sequences $\left(5^{\prime}-3^{\prime}\right)$ \\
\hline Gemin6F & gag gat ccc atg agt gaa tgg atg aag \\
Gemin6R & gcc tcg agt cat tgg gaa gct gta aga \\
Gemin7F & gag gat cca atg caa act cca gtg aac \\
Gemin7R & gcc tcg agt tat ggc ttg aag gta ta \\
Gemin3F & agt gac cta ctg ttg ccg g \\
Gemin3R & cat ctt cct ggg ctt cag tgc \\
Gemin 4F & atc gcg aat tcc atg gac cta gga ccc ttg \\
Gemin 4R & ata att ctc gag cag cac ctc gtc tgg ctc \\
Gemin 5FN & gca ctg gat cct cga gtc ata gga gag ttg \\
Gemin 5RN & gct cgg aag ctt cca tac acg gat cat gcc \\
Gemin 5FC & aat tag gat ccg atg gcc tcc tgg gac gag \\
\end{tabular}

the activity of SMN in a snRNP assembly assay can vary developmentally without changing SMN levels [44], though it is not known whether this requires any changes in SMN complex components. The present study suggests that gemin5 works only "part-time" as a component of SMN complexes, in the sense that they can exist without gemin5 and that gemin5 may have functions that are independent of SMN complexes, though possibly involving related assembly functions. In some ways, the behaviour of gemin5 resembles that of another WD-repeat protein, unrip, as reported either in this study or elsewhere.

\section{Methods}

\section{Cloning and expression of gemin cDNAs}

Total RNA was isolated from HeLa cells using an RNAeasy Midi Kit (Qiagen) and converted to cDNA using Sensiscript reverse transcriptase (Qiagen) and random hexamer primers. Specific gemin cDNA sequences were obtained by PCR using the primers shown in Table 3 . The primers contained restriction sites for cloning into pET21b or pET32b; EcoRI and XhoI for gemin4, BamHI and HindIII for gemin 5 and BamHI and XhoI for gemins 6 and 7. The gemin3 PCR product was cloned into the pT7Blue plasmid, cut from it using the plasmid BamHI and XhoI sites and subcloned into the same sites of pET21b. The cDNAs encoded aa 18-362 of gemin3, the first 650aa of gemin4, aa55-407 for gemin5 N-terminal region, aa 1217-1508 for gemin 5 C-terminal region and full-length for gemins 6 and 7. All constructs were sequenced to check for PCR errors. For immunogen production, gemins 3, 4 and Nterminal gemin 5 were expressed from pET21b and the rest from pET32b.

Transformed bacteria [E. coli BL21(DE3)] were induced with $1 \mathrm{mM}$ IPTG for $3 \mathrm{~h}$ at $37^{\circ} \mathrm{C}$. Expressed fusion protein was purified from inclusion bodies by sequential extraction with increasing concentrations ( $2 \mathrm{M}, 4 \mathrm{M}, 6 \mathrm{M}, 8 \mathrm{M})$ of urea in phosphate-buffered saline (PBS). The extracts in
$6 \mathrm{M}$ urea were then purified by affinity chromatography with His. Bind resin (Novagen).

\section{Production of antibodies}

Monoclonal antibodies were produced by immunization of BALB/c mice and fusion of spleen cells with Sp2/0 myeloma cells as described elsewhere [45]. Both the mouse sera and the hybridoma culture supernatants were screened by elisa, Western blot (HeLa total protein extract) and immunofluorescence microscopy (nuclear gems/CBs in HeLa cells). Hybridoma cell lines were cloned to homogeneity by limiting dilution. Ig subclass was determined using an isotyping kit (Zymed, San Francisco). Polyclonal antibodies were produced commercially by immunization of a New Zealand White rabbit with recombinant protein (Harlan SeraLab, Loughborough, UK).

Other antibodies used in this study were rabbit antiserum against SMN and mAbs MANSMA1 and MANSIP1A against SMN and gemin2 [31], mAb 5P10 against coilin p80 (gift of Angus Lamond, University of Dundee, UK [46]), human autoantiserum against fibrillarin (gift of K. Michael Pollard, Scripps, San Diego [33]), mAb MANEM5 against emerin [47], mAb MANLAC1 against lamin A/C [48], mAb PF2A3 against profilin II and rabbit antiserum against unrip [17], mAb 8226 against beta-actin and rabbit antiserum 11317 against gamma-tubulin (Abcam, Cambridge, UK).

\section{SDS-PAGE and western blotting}

SDS-PAGE and western blotting were carried out as described elsewhere [17]. Protein bands were visualized by development with peroxidase-conjugated rabbit anti(mouse Ig) (DAKOpatts) and a chemiluminescent system (SuperSignal; Pierce). Quantitation was performed by microdensitometry of captured blot images using Laserpix software (BioRad Laboratories). To minimize problems with non-linear response of X-ray film, several dilutions 
of cell extracts were blotted and those that gave the same, or similar, intensities in a linear response region were used for comparative quantitation.

\section{Immunohistochemistry}

HeLa, Ntera-2 (NT-2) and skin fibroblast (GM08333, control and GM03813, SMA from Coriell Cell Bank, Camden, NJ) cell lines and the stably-transfected SMN-overexpressor fibroblast cell line were grown on coverslips in DMEM with $10 \%$ horse serum and fixed with $1 \%$ formalin or 50:50 acetone-methanol. As shown previously [49], the levels of recombinant SMN over-expression in the stably-transfected cell line were similar to endogenous SMN levels, thus approximately doubling total SMN levels. Formalin-fixed cells were permeabilized with $1 \%$ Triton X100 and blocked with 1\% glycine before use. For double labeling experiments, coverslips were incubated with the mouse mAb for $1 \mathrm{~h}$, followed by the rabbit polyclonal antibody for $1 \mathrm{~h}$. Alexa488- or Alexa546-conjugated goat anti-(mouse Ig) and goat anti-(rabbit Ig) (Molecular Probes, Eugene, OR) were then applied. Nuclei were revealed with a DAPI counter stain and slides were viewed using the L4 filter set and a $63 \times$ oil immersion objective on a Leica DMRB photomicroscope. Images were captured using an integrating camera and frame-grabber under standard and comparable conditions.

\section{Subcellular fractionation studies}

300-600 ml of HeLa cells were grown in suspension culture for 4 days and washed in ice-cold PBS. The pellet was resuspended in 4 volumes of RIPA buffer (1\% NP40, $0.25 \%$ deoxycholate, $1 \mathrm{mM}$ EDTA, $1 \mathrm{mM}$ PMSF, $150 \mathrm{mM}$ $\mathrm{NaCl}, 50 \mathrm{mM}$ Tris-HCl pH 7.4), left on ice for 30 minutes, homogenizing every 10 minutes. The homogenate was centrifuged at $13,000 \mathrm{~g}$ for 15 minutes at $4^{\circ} \mathrm{C}$ and the supernatant retained. Cytoplasmic and nuclear fractions were prepared as described by Meister et al [20]. Briefly, HeLa cells were homogenized in $10 \mathrm{mM} \mathrm{KCl}, 10 \mathrm{mM}$ HEPES-KOH pH 7.9, $1.5 \mathrm{mM} \mathrm{MgCl}_{2}, 0.5 \mathrm{mM}$ PMSF and $0.5 \mathrm{mM}$ dithiothreitol and centrifuged for 10 minutes at $1000 \mathrm{~g}$ at $4^{\circ} \mathrm{C}$. The supernatant was clarified further at $13,000 \mathrm{~g}$ for 10 minutes at $4^{\circ} \mathrm{C}$ to produce the cytoplasmic fraction. The nuclear pellet was homogenized in $1 \mathrm{ml}$ of $420 \mathrm{mM} \mathrm{KCl}, 20 \mathrm{mM}$ HEPES-KOH pH 7.9, $1.5 \mathrm{mM}$ $\mathrm{MgCl}_{2}, 0.5 \mathrm{mM}$ PMSF, $0.2 \mathrm{mM}$ EDTA and 5\% glycerol, left for 30 minutes on ice and then centrifuged 13,000 $\mathrm{g}$ for 30 minutes at $4^{\circ} \mathrm{C}$. The supernatant was designated as the nuclear fraction.

RIPA extracts or cytoplasmic and nuclear fractions were analysed on $35 \mathrm{ml} 15-30 \%$ sucrose density gradients in $150 \mathrm{mM} \mathrm{NaCl}, 50 \mathrm{mM}$ Tris $\mathrm{HCl}$ pH 7.4 and $5 \mathrm{mM} \mathrm{MgCl}_{2}$ by centrifugation in a Beckmann SW28 rotor at 25,000 g for 21 hours at $4{ }^{\circ} \mathrm{C}$. Thirty fractions were collected and every other fraction was concentrated 10-fold using Strata- clean resin (Stratagene, Amsterdam, Netherlands) and analyzed by SDS-PAGE and western blotting.

\section{Authors' contributions}

LTH carried out most of the laboratory studies and helped to draft the manuscript. HRF designed and performed the HeLa PV and immunoprecipitation studies. LTL and TTL produced DNA constructs and cell lines for the study. AHMB participated in the design of the study and helped to draft the manuscript. GEM conceived of the study, participated in its design and coordination, contributed to hybridoma production and helped to draft the manuscript. All authors read and approved the final manuscript.

\section{Acknowledgements}

Supported by a research grant to GEM from Families of SMA. LTH was also supported financially by Medical and Scientific Aid to VietNam, Cambodia and Laos and by a UK Overseas Research Studentship (ORS). We thank Dr. Philip Young (Peninsula Medical School, Exeter, UK) for helpful comments on the manuscript.

\section{References}

I. Gubitz AK, Feng W, Dreyfuss G: The SMN complex. Exp Cell Res 2004, 296:5I-56.

2. Otter S, Grimmler M, Neuenkirchen N, Chari A, Sickmann A, Fischer U: A Comprehensive Interaction Map of the Human Survival of Motor Neuron (SMN) Complex. J Biol Chem 2007, 282:5825-5833.

3. Charroux B, Pellizzoni L, Perkinson RA, Yong J, Shevchenko A, Mann M, Dreyfuss G: Gemin4. A novel component of the SMN complex that is found in both gems and nucleoli. J Cell Biol 2000, 148: I I77-II86.

4. Baccon J, Pellizzoni L, Rappsilber J, Mann M, Dreyfuss G: Identification and characterization of Gemin7, a novel component of the survival of motor neuron complex. J Biol Chem 2002, 277:31957-31962.

5. Carissimi C, Saieva L, Gabanella F, Pellizzoni L: Gemin8 is required for the architecture and function of the survival motor neuron complex. J Biol Chem 2006, 28 1:37009-37016.

6. Liu Q, Fischer U, Wang F, Dreyfuss G: The spinal muscular atrophy protein, and its associated protein SIPI are in complex with spliceosomal snRNP proteins. Cell 1997, 90:1013-102I.

7. Massenet S, Pellizzoni L, Paushkin S, Mattaj IW, Dreyfuss G: The SMN complex is associated with snRNPs throughout their cytoplasmic assembly pathway. Mol Cell Biol 2002, 22:6533-654l.

8. Narayanan $U$, Achsel T, Luhrmann R, Matera AG: Coupled in vitro import of $U$ snRNPs and SMN, the spinal muscular atrophy protein. Mol Cell 2004, 16:223-234.

9. Carrel TL, McWhorter ML, Workman E, Zhang H, Wolstencroft EC, Lorson C, Bassell GJ, Burghes AH, Beattie CE: Survival motor neuron function in motor axons is independent of functions required for small nuclear ribonucleoprotein biogenesis. J Neurosci 2006, 26: I 1014-1 I022.

10. Bechade C, Rostaing P, Cisterni C, Kalisch R, La Bella V, Pettmann B, Triller A: Subcellular distribution of survival motor neuron (SMN) protein: possible involvement in nucleocytoplasmic and dendritic transport. Eur J Neurosci 1999, I I:293-304.

II. Pagliardini S, Giavazzi A, Setola V, Lizier C, Di Luca M, DeBiasi S, Battaglia G: Subcellular localization and axonal transport of the survival motor neuron (SMN) protein in the developing rat spinal cord. Hum Mol Genet 2000, 9:47-56.

12. Jablonka S, Bandilla M, Wiese S, Buhler D, Wirth B, Sendtner M, Fischer U: Co-regulation of survival of motor neuron (SMN) protein and its interactor SIPI during development and in spinal muscular atrophy. Hum Mol Genet 200I, I 0:497-505.

13. Fan L, Simard LR: Survival motor neuron (SMN) protein: role in neurite outgrowth and neuromuscular maturation during 
neuronal differentiation and development. Hum Mol Genet 2002, II:I605-1614.

14. Zhang HL, Pan F, Hong D, Shenoy SM, Singer HR, Bassell GJ: Active transport of the survival motor neuron protein and the role of exon-7 in cytoplasmic localization. J Neurosci 2003, 23:6627-6637.

15. Rossoll W, Jablonka S, Andreassi A, Kroning AK, Karle K, Monani M, Sendtner M: Smn, the spinal muscular atrophy-determining gene product, modulates axon growth and localization of $\beta$ actin mRNA in growth cones of motorneurons. J Cell Biol 2003, 163:80I-8I2.

16. McWhorter M, Monani UR, Burghes AHM, Beattie CE: Knockdown of the survival motor neuron (smn) protein in zebrafish causes defects in motor axon outgrowth and pathfinding. Cell Biol 2003, 162:919-931.

17. Sharma A, Lambrechts A, Le thi Hao, Le TT, Sewry CA, Ampe C, Burghes $A H$, Morris GE: A role for complexes of survival of motor neurons (SMN) protein with gemins and profilin in neurite-like cytoplasmic extensions of cultured nerve cells. Exp Cell Res 2005, 309:185-197.

18. Buhler D, Raker V, Luhrmann R, Fischer U: Essential role for the tudor domain of SMN in spliceosomal $U$ snRNP assembly: implications for spinal muscular atrophy. Hum Mol Genet 1999, 8:235I-2357

19. Mourelatos Z, Dostie J, Paushkin S, Sharma A, Charroux B, Abel L, Rappsilber J, Mann M, Dreyfuss G: miRNPs: a novel class of ribonucleoproteins containing numerous microRNAs. Genes Dev 2002, I 6:720-728.

20. Meister G, Buhler D, Laggerbauer B, Zobawa M, Lottspeich F, Fischer $\mathrm{U}$ : Characterization of a nuclear $20 \mathrm{~S}$ complex containing the survival of motor neurons (SMN) protein and a specific subset of spliceosomal Sm proteins. Hum Mol Genet 2000, 9:1977-1986

21. Meister G, Buhler D, Pillai R, Lottspeich F, Fischer U: A multiprotein complex mediates the ATP-dependent assembly of spliceosomal U snRNPs. Nat Cell Biol 200I, 3:945-949.

22. Hunt SL, Hsuan J], Totty N, Jackson RJ: unr, a cellular cytoplasmic RNA-binding protein with five cold-shock domains, is required for internal initiation of translation of human rhinovirus RNA. Genes Dev 1999, 13:437-448.

23. Carissimi C, Baccon J, Straccia M, Chiarella P, Maiolica A, Sawyer A, Rappsilber J, Pellizzoni L: Unrip is a component of SMN complexes active in snRNP assembly. FEBS Lett 2005, 579:2348-2354.

24. Ogawa C Usui K, Aoki M, Ito F, Itoh M, Kai C, Kanamori-Katayama $M$, Hayashizaki $Y$, Suzuki H: Gemin2 plays an important role in stabilizing the survival of motor neuron complex. J Biol Chem 2007, 282: III 22-IIII34.

25. Grundhoff AT, Kremmer E, Tureci O, Glieden A, Gindorf C, Atz J, Mueller-Lantzsch N, Schubach WH, Grasser FA: Characterization of DPI03, a novel DEAD box protein that binds to the Epstein-Barr virus nuclear proteins EBNA2 and EBNA3C. Biol Chem 1999, 274:19136-19144.

26. Carnegie KG, Sleeman JE, Morrice N, Hastie CJ, Peggie MW, Philip A, Lamond Al, Cohen PTW: Protein phosphatase 4 interact with the survival of motor neurons complex and enhances the temporal localisation of snRNPs. J Cell Sci 2003, I | 6: 1905-1913.

27. Grimmler M, Bauer L, Nousiainen M, Korner R, Meister G, Fischer U: Phosphorylation regulates the activity of the SMN complex during assembly of spliceosomal U snRNPs. EMBO Rep 2005 , 6:70-76.

28. Park JW, Voss PG, Grabski S, Wang JL, Patterson RJ: Association of galectin- $I$ and galectin-3 with Gemin 4 in complexes containing the SMN protein. Nucleic Acids Res 200I, 29:3595-3602.

29. Gubitz AK, Mourelatos Z, Abel L, Rappsilber J, Mann M, Dreyfuss G Gemin5, a novel WD repeat protein component of the SMN complex that binds Sm proteins. I Biol Chem 2002 277:563I-5636

30. Ma Y, Dostie J, Dreyfuss G, Van Duyne GD: The Gemin6-Gemin7 heterodimer from the survival of motor neurons complex has an Sm protein-like structure. Structure (Camb) 2005, 1 3:883-892

31. Young PJ, Le TT, Nguyen Thi Man, Burghes AHM, Morris GE: The relationship between SMN, the spinal muscular atrophy protein, and nuclear coiled bodies in differentiated tissues and cultured cells. Exp Cell Res 2000, 256:365-374.
32. Pereboev A, Morris GE: Reiterative screening of phage display peptide libraries. In "Epitope Mapping Protocols" Edited by: Morris GE. Humana Press, Totowa, NJ; 1996:195-206.

33. Takeuchi K, Turley SJ, Tan EM, Pollard KM: Analysis of the autoantibody response to fibrillarin in human disease and murine models of autoimmunity. J Immunol 1995, 154:961-97I.

34. Young PJ, Le TT, Dunckley M, Nguyen TM, Burghes AHM, Morris GE: Nuclear gems and Cajal (coiled) bodies in fetal tissues: nucleolar distribution of the spinal muscular atrophy protein, SMN. Exp Cell Res 200I, 265:252-26I.

35. Tunnah D, Sewry CA, Vaux D, Schirmer EC, Morris GE: The apparent absence of lamin $B I$ and emerin in many tissue nuclei is due to epitope masking. J Mol Histol 2005, 36:337-344.

36. Paushkin S, Gubitz AK, Massenet S, Dreyfuss G: The SMN complex, an assemblyosome of ribonucleoproteins. Curr Opin Cell Biol 2002, 14:305-312.

37. Battle DJ, Lau CK, Wan L, Deng H, Lotti F, Dreyfuss G: The Gemin5 protein of the SMN complex identifies snRNAs. Mol Cell 2006, 23:273-279.

38. Feng W, Gubitz AK, Wan L, Battle DJ, Dostie J, Golembe T], Dreyfuss G: Gemins modulate the expression and activity of the SMN complex. Hum Mol Genet 2005, I4:1605-1611.

39. Shpargel KB, Matera AG: Gemin proteins are required for efficient assembly of Sm-class ribonucleoproteins. Proc Natl Acad Sci USA 2005, I02: 17372-17377.

40. Fierro-Monti I, Mohammed S, Matthiesen R, Santoro R, Burns JS, Williams DJ, Proud CG, Kassem M, Jensen ON, Roepstorff P: Quantitative proteomics identifies Gemin5, a scaffolding protein involved in ribonucleoprotein assembly, as a novel partner for eukaryotic initiation factor 4E. J Proteome Res 2006, 5:1367-1378

4I. van Koningsbruggen S, Straasheijm KR, Sterrenburg E, de Graaf N, Dauwerse HG, Frants RR, van der Maarel SM: FRGIP-mediated aggregation of proteins involved in pre-mRNA processing. Chromosoma 2006, I I 6:53-64.

42. Grimmler M, Otter S, Peter C, Muller F, Chari A, Fischer U: Unrip, a factor implicated in cap-independent translation, associates with the cytosolic SMN complex and influences its intracellular localization. Hum Mol Genet 2005, I 4:3099-3 I I I.

43. Hebert MD, Shpargel KB, Ospina JK, Tucker KE, Matera AG: Coilin methylation regulates nuclear body formation. Dev Cell 2002, 3:329-337.

44. Gabanella F, Carissimi C, Usiello A, Pellizzoni L: The activity of the Spinal Muscular Atrophy protein is regulated during development and cellular differentiation. Hum Mol Genet 2005, I 4(23):4629-4642.

45. Nguyen thi Man, Morris GE: A rapid method for generating large numbers of high-affinity monoclonal antibodies from a single mouse. In "The Protein Protocols Handbook" 2nd edition. Edited by: Walker JM. Humana Press, Totowa, NJ; 2002: I I 29- I I 38.

46. Bohman K, Ferreira JA, Lamond Al: Mutation analysis of p80 coilin indicates a function interaction between coiled bodies and the nucleus. / Cell Biol 1995, I 3 I:8I7-83 I.

47. Manilal S, Nguyen thi Man, Sewry CA, Morris GE: The Emery-Dreifuss muscular dystrophy protein, emerin, is a nuclear membrane protein. Hum Mol Genet 1996, 5:80I-808.

48. Manilal S, Randles KN, Aunac C, Nguyen M, Morris GE: A lamin A $C$ beta-strand containing the site of lipodystrophy mutations is a major surface epitope for a new panel of monoclonal antibodies. Biochim Biophys Act 2004, 167 I (I-3):87-92.

49. Le TT, Coovert DD, Monani UR, Morris GE, Burghes AH: The survival motor neuron (SMN) protein: effect of exon loss and mutation on protein localization. Neurogenetics 2000, 3:7-16. 